\title{
Effects of bedrest on deltoideus muscle morphology and enzymes
}

\author{
D. DESPLANCHES,${ }^{1}$ H. HOPPELER,${ }^{2}$ M. H. MAYET,${ }^{1}$ C. DENIS,${ }^{3}$ \\ H. CLA A S E N ${ }^{2}$ and G. FERRETTI ${ }^{4}$ \\ 1 UMR 5578 CNRS, Laboratoire de Physiologie, Universite' Lyon I, F-69373 Lyon Cedex 08, France \\ 2 Anatomisches Institut, Universität Bern, CH-3000 Bern, Switzerland \\ 3 Laboratoire de Physiologie-G.I.P. Exercice, Faculté de Médecine, F-42023 St Etienne Cedex 2, France \\ 4 Departement de Physiology, Centre Médical Universitaire, 1211 Geneva 4, Switzerland
}

\begin{abstract}
To examine the effects of unweighting on the structural and metabolic adaptations of a non-postural muscle, deltoideus muscle biopsies were taken in seven male healthy subjects, before and after a 37 day bedrest. Myofibrillar ATPase histochemistry demonstrated no change in fibre type distributions (I, IIA, IIB), in fibre cross-sectional areas nor in capillary supply. No difference was noted in enzyme activities of oxidative metabolism (citrate synthase, 3-hydroxy-acyl-CoA dehydrogenase), and glycolysis (hexokinase, lactate dehydrogenase). Electron microscopy showed a decrease in the volume density of lipids but no change in mitochondrial volume density and distribution. The results indicate that bedrest induces no major morphological and biochemical changes in deltoideus muscle, contrary to what was previously reported in vastus lateralis muscle. This lack of changes is probably related to an unaltered deltoideus muscle use.
\end{abstract}

Keywords bedrest, capillary, enzymes, fibre types, mitochondria, muscle.

Received 7 April 1997, accepted 22 September 1997

A progressive weakness of the antigravity skeletal muscles is commonly associated with exposure to microgravity. This is generally attributed to muscle atrophy (Jaweed 1994, Edgerton et al. 1995, LeBlanc et al. 1995). To better understand the factors responsible for muscle atrophy, human earth-based models have been developed, including a unilateral lower limb unloading model (Berg et al. 1991) and experimental bedrest (see Saltin \& Rowell 1980). After 17 weeks of bedrest, it has previously been demonstrated using magnetic resonance imaging that most of the lost lean tissue mass is from the lower limbs, with only small changes occurring in back muscle volume relative to the thigh and calf (Leblanc et al. 1992). In legs, extensor muscles show a greater atrophy than flexor muscles, due to the removal of their function in supporting body weight. By contrast, no change is observed in arm and trunk muscles. These results suggest that a major factor for muscle atrophy is the absence of muscle weight-bearing load.

Muscle data from biopsies of muscles exposed to simulated or real microgravity are scarce and most of them concern lower limb muscles (i.e. vastus lateralis muscle; Saltin \& Rowell 1980, Hikida et al. 1989, Larsson et al. 1996, Berg et al. 1997, Ferretti et al. 1997). It has been shown previously that bedrest induces a reduction in slow- and fast-twitch fibre cross-sectional areas as well as in muscle oxidative capacity (oxidative enzyme activities, mitochondrial volume density, total capillary length; Ferretti et al. 1997). Alterations in contractile properties have also been reported, such as a drop in single fibre maximum force (normalized to fibre cross-sectional areas; Larsson et al. 1996), whereas the percentage distribution of fibres and the expression of myosin heavy chain isoforms remain unchanged (Berg et al. 1997, Ferretti et al. 1997). To our knowledge, no data concerning the effects of reduced activity and loading during a bedrest period on the structural characteristics of a non-postural muscle are currently available.

The purpose of the present study was therefore to provide information concerning the effects of a 37 day bedrest on the deltoideus muscle with regard to its 
structural composition and the activities of oxidative and glycolytic enzymes. It was hypothesized that bedrest would not significantly affect an upper body muscle in its structural composition or in the activities of key enzymes of the major metabolic pathways, as bedrest would not significantly alter use of upper body musculature.

\section{MATERIAL AND METHODS}

\section{Subjects}

Seven healthy young male subjects (mean age, $28 \pm 1$ years; average height, $176.4 \pm 1.3 \mathrm{~cm}$; and weight, $74.0 \pm 3.3 \mathrm{~kg}$ ) volunteered to participate in a 42 day period of head-down tilt $\left(-6^{\circ}\right)$ bedrest at Purpan Hospital in Toulouse, France. They all gave their informed consent. Throughout the bedrest, the subjects were not allowed to leave a strict horizontal position or to exercise. Deltoideus muscles used extensively for arm abduction were often active. During meal-times, subjects lay flat on their stomachs, taking meals on a low table in front of their bed. They lifted their elbows when reading.

The bedrest was organized by the Institut de Médecine et de Physiologie Spatiales (MEDES) and was approved by the Comite consultatif de protection des personnes dans la recherche biomédicale, Toulouse I, France. It was supported by European Space Agency and Centre National d'Etudes Spatiales.

\section{Skeletal muscle biopsies}

Muscle biopsies were taken under local anaesthesia from the same location and depth on the midportion of muscle deltoideus, 29 days before bedrest and during the 37th day of bedrest, using a Weil-Blakesley conchotome (Henriksson 1979). Samples were divided for histochemistry, biochemistry and electron microscopy. Due to the ethical considerations of multiple sampling in subjects, our data are based on a single biopsy. It should be noted that care must be exercised in the interpretation of our study as there is some risk of not detecting significant differences after bedrest. Blomstrand \& Ekblom (1982) found that the difference in fibre type composition between two biopsies taken from the same muscle site in a subject may be as large as $20 \%$ or even more. This biological variation is important in our study, which includes repeated biopsies from the same muscle at different times (pre- and postbedrest). Capillary per fibre ratio and capillary density, volume density of myofibrils and mitochondria, oxidative and glycolytic enzyme activities will be determined in muscle samples with some variation between the different fibre types.

\section{Histochemical analysis}

A $5 \mathrm{~mm}$ thick block was mounted in an embedding medium (TEK ACT compound), frozen in isopentane pre-cooled in liquid nitrogen, and stored at $-80{ }^{\circ} \mathrm{C}$ until analysis. Serial transverse sections $(10 \mu \mathrm{m})$ were cut on a microtome at $-30{ }^{\circ} \mathrm{C}$ and were stained for myofibrillar adenosinetriphosphatase (ATPase) activity (Brooke \& Kaiser 1970). After preincubation at different $\mathrm{pH}$ values $(4.3,4.5)$ in acid buffer (acetic acid $50 \mathrm{~mm}$ ) with $25 \mathrm{~mm} \mathrm{CaCl}$ for $4 \mathrm{~min}$ at $25^{\circ} \mathrm{C}$, the ATPase reaction was carried out in a buffer ( $\mathrm{pH} 9.4)$ with $18 \mathrm{mM} \mathrm{CaCl}_{2}$ and $2.7 \mathrm{~mm}$ ATP at $37^{\circ} \mathrm{C}$ for $20 \mathrm{~min}$. Based on observed differences in $\mathrm{pH}$ lability of the myosin ATPase activity of the isomyosins in the different fibres, muscle fibres were classified into three major types (I, IIA, and IIB). Intermediate fibres (IIC) were only seen in one subject $(1.8 \%)$ before bedrest. Fibre type composition is expressed as the number of fibres of each type relative to the total number of fibres. Measurements were made on $354 \pm 66$ (mean \pm SD) fibres on each section. The fibre cross-sectional areas were calculated using a computerized planimetry system coupled to a digitizer. Mean fibre area is expressed as the amount of 70 fibres divided by the number of fibres. Capillaries were stained using the ATPase technique after preincubation at $\mathrm{pH}$ 4.0. Capillary density and capillaries per fibre were determined as described by Andersen \& Henriksson (1977).

\section{Enzyme assays}

Muscle samples $(10 \mathrm{mg})$ were weighed and immediately homogenized (between 0 and $-4{ }^{\circ} \mathrm{C}$ ) in $0.3 \mathrm{M}$ phosphate buffer containing $0.05 \%$ bovine serum albumin $(\mathrm{pH}$ 7.7) using a glass Potter-Elvehjem homogenizer. They were frozen at $-80{ }^{\circ} \mathrm{C}$ and thawed three times to disrupt the mitochondrial membrane. Enzyme activities were determined at $25^{\circ} \mathrm{C}$. Hexokinase (HK, EC 2.7.1.1), lactate dehydrogenase (LDH, EC 1.1.1.27) and 3-hydroxyacyl-CoA dehydrogenase (HAD, EC 1.1.1.35) were fluorimetrically determined as previously described by Lowry \& Passonneau (1973). Citrate synthase (C.S., EC 4.1.3.7) was measured by the method of Srere (1969) using 5-5'-dithiobis (2-nitrobenzoic acid). On the basis of wet muscle weight, enzyme activities are expressed as micromoles substrate per minute per gram protein.

\section{Morphometry}

A fraction of the muscle tissue was processed for electron microscopy by fixation in a $6.25 \%$ solution of glutaraldehyde as previously described (Hoppeler et al. 1981). Ultrathin sections $(60-90 \mathrm{~nm})$, transverse with 
Table 1 Percentage distribution (\%) and areas $\left(\mu \mathrm{m}^{2}\right)$ of fibre types in the deltoideus muscle before and after bedrest. Values are means $\pm \mathrm{SD}$ for seven subjects

\begin{tabular}{llllll}
\hline & \multicolumn{2}{l}{ Percentage distribution of fibres $(\%)$} & & \multicolumn{2}{l}{ Fibre areas $\left(\mu \mathrm{m}^{2}\right)$} \\
\cline { 2 - 3 } \cline { 5 - 6 } & Before & After & & Before & After \\
\hline I & $59.8 \pm 12.9$ & $58.6 \pm 8.0$ & & $4142 \pm 582$ & $4546 \pm 1160$ \\
IIA & $18.7 \pm 5.8$ & $21.7 \pm 6.6$ & & $6002 \pm 1218$ & $7077 \pm 2177$ \\
IIB & $21.5 \pm 10.6$ & $19.7 \pm 7.8$ & & $5528 \pm 1189$ & $6422 \pm 1619$ \\
\hline
\end{tabular}

regard to the fibre axis, were cut with an LBK ultramicrotome from two tissue blocks randomly chosen from each muscle. For analysis of the mitochondria, lipid droplets and myofibrils, 40 micrographs per muscle (20 per block) were taken on $35 \mathrm{~mm}$ film with a Philips 300 electron microscope at a final magnification of $\times 24000$. The volume densities of interfibrillar mitochondria, subsarcolemmal mitochondria, intramyocellular lipid droplets and myofibrils were determined with a systematic sampling procedure by photographing tissues consistently in consecutive frames of 200 square mesh grids. The reference space was the total fibre volume. The mean total volume density of mitochondria was calculated as the sum of the mean interfibrillar and subsarcolemmal mitochondrial volume densities for each muscle. Point counting was performed with a grid C 16 (144 test points). All stereological variables were estimated according to standard procedures (Weibel 1979).

\section{Statistics}

The Wilcoxon rank-sum test was used to test the significance of intragroup differences (before and after bedrest). Linear regression analysis was performed according to standard procedures. The level of significance was set at $\mathrm{P}<0.05$. All data are expressed as means $\pm \mathrm{SD}$.

\section{RESULTS}

The percentage distribution and cross-sectional areas of fibres are shown in Table 1 . The relative percentage of type I, IIA and IIB fibres remained unchanged. The seven subjects exhibited no atrophy at all. Neither capillary per fibre ratio $(2.37 \pm 0.29$ vs. $2.23 \pm 0.17)$ nor capillary density $\left(471 \pm 71\right.$ vs. $\left.430 \pm 99 \mathrm{~mm}^{-2}\right)$ was affected by bedrest. Calculated coefficients of variation $(\mathrm{CV})$ reached 18 and $30 \%$ for the proportion of type I and IIA fibres, and were higher (44\%) for the proportion of type IIB fibre. Mean cross-sectional areas of the different fibres exhibited a CV of $23 \%$. CV reached $10 \%$ for capillary per fibre ratio and $20 \%$ for capillary density.

The stereological variables are presented in Table 2. No change occurred in the volume density of mito- chondria and myofibrils. In contrast, the volume density of lipids was decreased significantly by $42 \%$.

Muscle enzyme activities are reported in Figure 1. A high coefficient of correlation exists between the volume density of mitochondria and the activity of citrate synthase $(r=0.71, P<0.05)$. Exposure to bedrest induced no alteration in citrate synthase $(24.7 \pm 7.1$ vs. $26.9 \pm 9.9 \mu \mathrm{mol} \mathrm{g}$ prot $^{-1} \mathrm{~min}^{-1}$ ) or in 3 hydroxyacylCoA dehydrogenase $(19.2 \pm 2.9$ vs. $23.4 \pm 6.7 \mu \mathrm{mol}$ $\mathrm{g} \operatorname{prot}^{-1} \mathrm{~min}^{-1}$ ) activities. With respect to glycolytic potential, bedrest had no significant influence on lactate dehydrogenase $(870 \pm 318$ vs. $957 \pm 457 \mu \mathrm{mol} \mathrm{g}-$ prot $\left.^{-1} \mathrm{~min}^{-1}\right)$ or hexokinase $(3.1 \pm 0.6$ vs. $3.8 \pm$ $1.1 \mu \mathrm{mol} \mathrm{g}$ prot $^{-1} \mathrm{~min}^{-1}$ ) activities. The coefficient of variation ranged between 15 and $37 \%$ for the activity of oxidative enzyme markers (CS, HAD), and between 19 and $45 \%$ for the glycolytic enzyme markers (HK, LDH). CV reached 21, 3 and 39\% for the volume density of total mitochondria, myofibrils and lipids.

In our study, data are based on a single biopsy. Because of the large variability in the proportion of the fibre types within a whole muscle, we have tried to predict the number of individuals that would have been needed to detect a difference in muscle parameters studied before and after bedrest (Daniel 1995). We considered the probability of committing a type I error (rejecting a true null hypothesis, $\alpha=0.05$ ) as well as a type II error (failing to reject a false null hypothesis, $\beta=0.05)$ when determining the sample size. If only one biopsy is taken, the number of subjects ranged between 9 with regard to percentage type IIA fibre and 1574 with regard to percentage type I fibre. This

Table 2 Effects of bedrest on volume densities of mitochondria, lipids and myofibrils. Volume density $\left(V_{\mathrm{v}}\right.$, as a percentage) for interfibrillar (subscript mi, f), subsarcolemmal (ms, f) and total (mt, f) mitochondria, and for lipids (li, f) and myofibrils (fi, f). Values are means $\pm \mathrm{SD}, n=7$ subjects. ${ }^{*}$, significantly different before and after bedrest $(P<0.05)$

\begin{tabular}{lll}
\hline & Before & After \\
\hline$V_{\mathrm{v}(\mathrm{mi}, \mathrm{f})}$ & $3.85 \pm 0.60$ & $4.06 \pm 0.92$ \\
$V_{\mathrm{v}(\mathrm{ms}, \mathrm{f})}$ & $0.67 \pm 0.33$ & $0.48 \pm 0.22$ \\
$V_{\mathrm{v}(\mathrm{mt}, \mathrm{f})}$ & $4.52 \pm 0.75$ & $4.54 \pm 1.08$ \\
$V_{\mathrm{v}(\mathrm{li}, \mathrm{f})}$ & $0.62 \pm 0.19$ & $0.36 \pm 0.17^{*}$ \\
$V_{\mathrm{v}(\mathrm{fi}, \mathrm{f})}$ & $78.2 \pm 2.21$ & $78.6 \pm 2.1$ \\
\hline
\end{tabular}



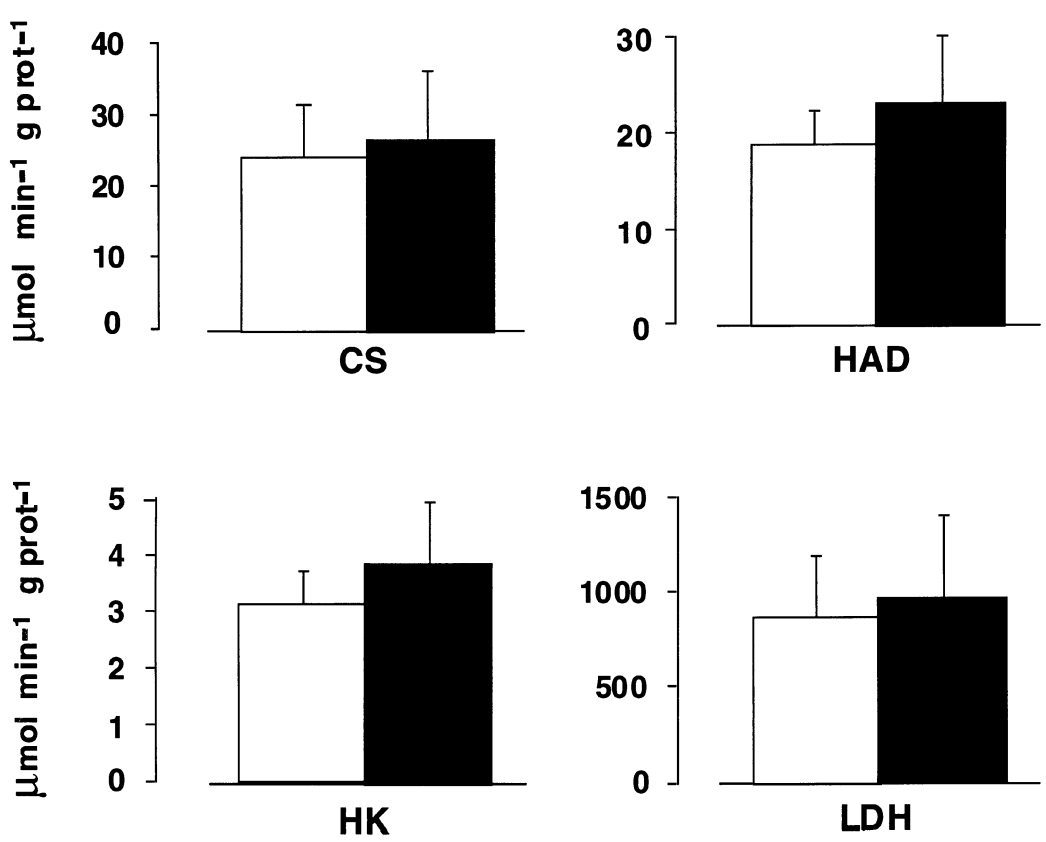

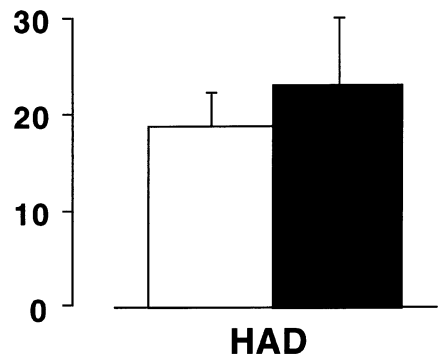

HAD

Figure 1 Enzyme activities before $(\square)$ and after $(\square)$ bedrest. CS, citrate synthase; HAD, 3-hydroxyacyl-CoA dehydrogenase; HK, hexokinase; LDH, lactate dehydrogenase. Each bar represents the mean \pm SD. number is $>40$ to find some significant differences in the mean fibre cross-sectional areas.

\section{DISCUSSION}

In the deltoideus muscle, the percentage distribution and cross-sectional areas of type I fibres before bedrest were similar to those previously observed for normally active controls (see Tesch \& Karlsson 1985, Flynn et al. 1987). The deltoideus muscle developed no fibre atrophy, contrary to what was reported in the vastus lateralis muscle of the same subjects after a 37 day bedrest (Berg et al. 1997, Ferretti et al. 1997). This lack of atrophy can probably be attributed to the fact that the muscles of the upper body have no weight-bearing function and are always active.

Based on myosin ATPase histochemistry, fibres were routinely classified in three major fibre types, type I, IIA and IIB. However, it should be noted that recent human studies suggest that the previously classified IIB muscle fibres contain myosin heavy chain (MHC) isoforms and MHC transcripts similar to those found in the rat IIX fibres and would be more accurately classified as IIX fibres (Smerdu et al. 1994, Ennion et al. 1995, Sant'Ana Pereira et al. 1995). The histochemical findings of this study demonstrate that the percentage distribution of fibres remained unchanged after bedrest, consistent with previous human vastus lateralis muscle data during the same bedrest (Berg et al. 1997, Ferretti et al. 1997). However, early studies in which the physical activity was reduced by detraining, immobilization with a plaster cast or amputation have reported the possibility of fibre type transformation, a lower fibre type I percentage being observed (see Schantz 1986). This has been further supported by results from rat (soleus) and human (vastus lateralis) lower limb muscles exposed to 6 or 11 days spaceflight missions, which showed a decrease in the percentage of slow fibres and an increase in the percentage of fast fibres (Caiozzo et al. 1994, Edgerton et al. 1995). We have to point out that we do not yet know to what degree bedrest simulates microgravity specifically for the upper body, including shoulder muscles that have to work against gravity during bedrest but not during real spaceflight.

With respect to oxidative capacity, bedrest induced no alterations in the total mitochondrial volume density or in oxidative enzyme activites (citrate synthase and 3-hydroxyacyl-CoA dehydrogenase). A close correlation was found between the morphometric estimation of muscle oxidative capacity and mitochondrial enzyme activities such as citrate synthase, which is in agreement with the findings of Reichman et al. (1985). During the same bedrest, a large reduction in those parameters describing muscle oxidative capacity had been observed in the vastus lateralis muscle, suggesting different responses in postural and non-postural muscles (Ferretti et al. 1997). Previous studies indicate that shoulder/arm and leg muscles may react differently to a change in use. For example, endurance training for 6 weeks of the same relative intensity and duration with arms and legs induces different muscle structural adaptations (Turner et al., unpubl. obs.). In the deltoideus muscle, the increased total mitochondrial absolute volume was mainly achieved by increasing muscle volume, while in the vastus lateralis muscle it was due to the increased volume density of mitochondria. It has also previously been shown that after 8 weeks of bicycle endurance training, the volume density of mitochondria decreased 
by $17 \%$ in the untrained deltoideus muscle, while it was increased by $40 \%$ in the trained vastus lateralis muscle (Rösler et al. 1985). In addition, fine differences exist in the essential myosin light chain mRNA expression of shoulder (deltoideus) and leg (vastus lateralis) muscles (Jostarndt et al. 1996), which could originate either in the ontogenesis of fore- and hindlimbs (Ordhal \& Le Douarin 1992) or from different patterns of use (Booth \& Thomason 1991).

After bedrest, glycolytic enzyme activities were not altered. The only significant alteration in the metabolic parameters which were analysed in that study consists of a significant decrease of the volume density of lipids while the activity of a $\beta$ oxidation marker enzyme (3hydroxyacyl-CoA dehydrogenase) remains unchanged. These findings need to be confirmed and expanded as no change occurred in the intracellular lipid content of vastus lateralis muscle fibres (Ferretti et al. 1997). Increase of intracellular lipid droplets are usually observed with endurance exercise training (Hoppeler et al. 1985). It is currently unclear whether dietary changes can influence intracellular lipid accumulation; however, an effect of diet on lipid stores in muscle cannot be excluded. Low muscle lipid contents are generally found in altitude-born natives (Kayser et al. 1996); however, these findings seem related to the fact that hypoxia favours carbohydrate metabolism (Brooks et al. 1991). The finding of a decreased intramyocellular lipid concentration remains currently unexplained. The following hypotheses may be considered. Dietary influences or bedrest-induced hormonal changes associated with reduced physical activity could contribute towards a decrease in the volume density of intracellular lipid stores. During this bedrest, a decrease in body weight which paralleled the reduction in energy intake was observed up to the seventh week (Blanc et al., unpubl. obs.). With respect to hormonal status, catecholamines could be involved in the reduction of muscle lipid stores, but two indirect indexes of sympathetic nervous activity, the urinary excretion of metanephrine and normetanephrine, were decreased throughout the bedrest, which makes this explanation unlikely. In contrast, previous rat muscle data indicate an accumulation of triglycerides (Musacchia et al. 1992) and a reduction in the capacity to oxidise long-chain fatty acids (Baldwin et al. 1993) after spaceflight.

In conclusion, the present study suggests that bedrest does not affect upper body muscles, i.e. deltoideus, except for a decrease in its lipid substrate stores. This can probably be explained by the fact that during bedrest, upper body muscles still work against gravity.

The authors express their sincere gratitude to Professor L. Larsson for taking biopsies from deltoideus muscle, and to the test subjects. This study was part of the HTD 94 Bed Rest project of the European Space Agency (ESA), which was jointly organized by the ESA and by the Centre National d'Etudes Spatiales (CNES), Toulouse, France. The subjects' selection, the logistic support for the experiments, the scientific coordination among groups and the medical follow-up of the subjects during the bedrest period were warranted by the Institut de Médecine et Physiologie Spatiales, Toulouse, France. We acknowledge the research and clinical staff, A. Maillet, G. Weerts and J. Le Kernau. This study was financially supported by ESA and by a grant from CNES (94/0395), the Swiss Federal School of Sport Sciences and the Italian Space agency.

\section{REFERENCES}

Andersen, P. \& Henriksson, J. 1977. Capillary supply of the quadriceps femoris muscle of man: adaptative response to exercise. J Physiol 270, 677-690.

Baldwin, K. Herrick, R.E. \& Mc Cue, S.A. 1993. Substrate oxidation capacity in rodent skeletal muscle: effects of exposure to zero gravity. J Appl Physiol 75, 2466-2470.

Berg, H.E., Dudley, G.A., Häggmark T, Ohlsen, H. \& Tesch, P.A. 1991. Effects of lower limb unloading on skeletal muscle mass and function in humans. J Appl Physiol 70, 1882-1885.

Berg, H.E., Larsson, L. \& Tesch, P.A. 1997. Lower limb skeletal muscle function after 6 weeks of bedrest. $J$ Appl Physiol 82, 182-188.

Blomstrand, E. \& Ekblom, B. 1982. The needle biopsy technique for fibre type determination in human skeletal muscle - a methodological study. Acta Physiol Scand 116, 437-442.

Booth, F.W. \& Thomason, D.B. 1991. Molecular and cellular adaptation of muscle in response to exercise: perspectives of various models. Physiol Rev 71, 541-585.

Brooke, M.H. \& Kaiser, K.K. 1970. Muscle fiber types: how many and what kind? Arch Neurol 23, 369-379.

Brooks, G.A., Butterfield, G.E., Wolfe, R.R., Groves, B.M., Mazzeo, R.S., Sutton, J.S., Wolfel, E.E. \& Reeves, J.T. 1991. Increased dependence on blood glucose after acclimatization to $4300 \mathrm{~m}$. J Appl Physiol 70, 919-927.

Caiozzo, V.J., Baker, M.J., Herrick, R.E. \& Baldwin, K.M. 1994. Effect of spaceflight on skeletal muscle: mechanical properties and myosin isoform content of a slow antigravity muscle. J Appl Physiol 76, 1764-1773.

Daniel, W.W. 1995. Biostatistics: a foundation for analysis in the bealth sciences. Wiley, New York.

Edgerton, V.R., Zhou, M.H., Ohira, Y., Klitgaard, H., Jiang, B., Bell, G., Harris, B., Saltin, B., Gollnick, P.D., Roy, R.R., Day, M.K. \& Greenisen, M. 1995. Human fiber size and enzymatic properties after 5 and 11 days of spaceflight. $J$ Appl Physiol 78, 1733-1739.

Ennion, S., Sant'Ana Pereira, J., Sargeant, A.J., Young, A. \& Goldspink, G. 1995. Characterization of human skeletal muscle fibres according to the myosin heavy chains they express. J Muscle Res Cell Motil. 16, 35-43.

Ferretti, G. Antonutto, G., Denis, C., Hoppeler, H., Minetti, A.L., Narici, M.V. \& Desplanches, D. 1997. The interplay of central and peripheral factors in limiting maximal $\mathrm{O}_{2}$ consumption in man: the effects of prolonged bedrest. J Physiol 501, 677-686.

Flynn, M.G., Costill, D.L., Kirwan, J.P., Fink, W.J. \& Dengel, D.R. 1987. Muscle fiber composition and respiratory capacity in triathletes. Int J Sports Me. 8, 383-386. 
Henriksson, K.G. 1979. Semi-open muscle biopsy technique. A simple outpatient procedure. Acta Neurol Scand 59, 317-323.

Hikida, R.S., Gollnick, P.D., Dudley, G.A., Convertino, V.A. \& Buchanan, P. 1989. Structural and metabolic characteristics of human skeletal muscle following 30 days of simulated microgravity. Aviat. Space Environ Med 60, 664-670.

Hoppeler, H., Howald, H. Conley, K.E., Lindstedt, S.L., Claassen, H., Vock, P. \& Weibel, E.R. 1985. Endurance training in humans: aerobic capacity and structure of skeletal muscle. J Appl Physiol 50, 320-327.

Hoppeler, H., Mathieu, O., Krauer, R., Claassen, H., Armstrong, R.B. \& Weibel, E.R. 1981. Design of the mammalian respiratory system. VI. Distribution of mitochondria and capillaries in various muscles. Respir Physiol 44, 87-111.

Jaweed, M.M. 1994. Muscle structure and function. In: A.E. Nicogossian, C.L. Huntoon \& S.L. Pool (eds) Space physiology and medicine, pp. 317-325. Lea \& Febiger, Philadelphia.

Jostarndt, K., Puntschart, A., Hoppeler, H. \& Billeter, R. 1996. Fiber type-specific expression of essential (alkali) myosin light chains in human skeletal muscles. $J$ Histochem Cytochem 44, 1141-1152.

Kayser, B., Hoppeler, H., Desplanches, D., Marconi, C., Broers, B. \& Cerretelli, P. 1996. Muscle ultrastructure and biochemistry of lowland Tibetans. J Appl Phsyiol 81, 419425.

Larsson, L., Xiaopeng, L., Berg, H.E. \& Frontera, W.R. 1996. Effects of removal of weight-bearing function on contractility and myosin isoform composition in single human skeletal muscle cells. Pflïgers Arch 432, 320-328.

LeBlanc, A., Rowe, R., Schneider, V., Evans, H. \& Hedrick, T. 1995. Regional muscle loss after short duration spaceflight. Aviat Space Environ Med 66, 1151-1154.

LeBlanc, A.D., Schneider, V.S., Evans, H.J., Pientok, C., Rowe, R. \& Spector, E. 1992. Regional changes in muscle mass following 17 weeks of bedrest. J Appl Physiol. 73, 2172-2178.

Lowry, O.H. \& Passonneau, J.V. 1973. Measurement of enzyme activities with pyridine nucleotides. In O.H. Lowry
\& J.V. Passonneau (eds) A flexible system of ensymatic analysis, pp. 93-109. Academic Press, New York.

Musacchia, X.J., Steffen, J.M., Fell, R.D., Dombrowski, M.J., Oganov, V.W. \& Ilyina-Kakueva, E.I. 1992. Skeletal muscle atrophy in response to 14 days of weightlessness: vastus medialis. J Appl Physiol 73, 44S-50S.

Ordahl, C.P. \& Le Douarin, N.M. 1992. Two myogenic lineages within the developing somite. Development 114, 339-353.

Reichmann, H., Hoppeler, H., Mathieu-Costello, O., Von Bergen, F. \& Pette, D. 1986. Biochemical and ultrastructural changes of skeletal muscle mitochondria after chronic electrical stimulation in rabbits. Pflügers Arch 404, 1-9.

Rösler, K.H., Hoppeler, H., Conley, K.E., Claassen, H., Gehr, P. \& Howald, H. 1985. Transfer effects in endurance exercise. Adaptations in trained and untrained muscles. Eur J Appl Physiol 54, 355-362.

Saltin, B. \& Rowell, L.B. 1980. Functional adaptations to physical activity and inactivity. Federation Proc 39, 1506-1513.

Sant'Ana Pereira, J.A.A., Wessels, A., Nitjmans, L., Moorman, A.F.M. \& Sargeant, A.J. 1995. New method for the accurate characterization of single human skeletal muscle fibres demonstrates a relation between mATPase and $\mathrm{MyHC}$ expression in pure and hybrid fibre types. J. Muscle Res Cell Motil 16, 21-34.

Schantz, P.G. 1986. Plasticity of human skeletal muscle. Acta Physiol Scand 128 (suppl. 558), 1-62.

Smerdu, V. Karsch-Mizrachi, I., Campione, M., Leinwand, L. \& Schiaffino, S. 1994. Type IIx myosin heavy chain transcripts are expressed in type IIb fibers of human skeletal muscle. Am J. Physiol 267, C1723- C1728.

Srere, P.A. 1969. Citrate synthase. Methods Ensymol 13, 3-5.

Tesch, P.A. \& Karlsson, J. 1985. Muscle fiber types and size in trained and untrained muscles of elite athletes. J Appl Physiol 59, 1716-1720.

Weibel, E.R. 1979. Stereological methods. practical methods for biological morphometry, chs 4, 6. Academic Press, London. 